\title{
Guillaume de Palerne, texte présenté et traduit par Christine Ferlampin-Acher
}

\section{Maria Colombo Timelli}

\section{(2) OpenEdition}

1 Journals

Édition électronique

URL : http://journals.openedition.org/studifrancesi/2060

DOI : 10.4000/studifrancesi.2060

ISSN : 2427-5856

Éditeur

Rosenberg \& Sellier

\section{Édition imprimée}

Date de publication : 1 avril 2014

Pagination : 117

ISSN : 0039-2944

\section{Référence électronique}

Maria Colombo Timelli, « Guillaume de Palerne, texte présenté et traduit par Christine Ferlampin-Acher », Studi Francesi [En ligne], 172 (LVIII | I) | 2014, mis en ligne le 01 avril 2014, consulté le 18 septembre 2020. URL : http://journals.openedition.org/studifrancesi/2060 ; DOI : https://doi.org/10.4000/ studifrancesi.2060

Ce document a été généré automatiquement le 18 septembre 2020.

\section{(c) (†) $\odot$}

Studi Francesi è distribuita con Licenza Creative Commons Attribuzione - Non commerciale - Non opere derivate 4.0 Internazionale. 


\title{
Guillaume de Palerne, texte présenté et traduit par Christine Ferlampin- Acher
}

\author{
Maria Colombo Timelli
}

\section{RÉFÉRENCE}

Guillaume de Palerne, texte présenté et traduit par Christine FERLAMPIN-ACHER, Paris, Classiques Garnier, 2012 («Moyen Âge en traduction», 1), pp. 289.

1 Transmis par un manuscrit unique (Arsenal, 6565), Guillaume de Palerne est un roman anonyme, ni arthurien ni antique: si son classement demeure difficile, il se nourrit de motifs en partie inspirés du folklore (notamment pour la métamorphose d'un des protagonistes en loup-garou), en partie certainement littéraires; récit agréable, aujourd'hui relativement peu connu, il mérite d'être redécouvert, ne fût-ce que sous la forme d'une traduction en français moderne.

2 L'Introduction, très développée (pp. 7-112), est consacrée à plusieurs questions littéraires. Est d'abord discuté le classement générique (Un roman idyllique?, pp. 11-18): Christine Ferlampin-Acher souligne surtout les traits communs avec d'autres romans, Guillaume d'Angleterre et en partie Guillaume de Dole, qu'elle propose de définir «romans de tiers état» (p. 16). Le rapport avec L'Escoufle, copié dans le même manuscrit de l'Arsenal, doit aussi être examiné (L'Escoufle et Guillaume de Palerne: un manuscrit pour deux romans, pp. 18-32): parmi les analogies entre ces deux œuvres, on retiendra une géographie réaliste, des récurrences onomastiques, des reprises de la matière tristanienne, sans que cela annule les différences voire certaines divergences (analysées ici pp. 27-29). Quoi qu'il en soit, la transmission de deux romans dans un seul et même codex mérite d'être retenue et approfondie.

Les éléments relatifs à la datation et à la transmission du roman sont réunis et discutés pp. 32-48; la date de composition de Guillaume de Palerne demeure en effet sujette à 
caution: si Alexandre Micha, éditeur du texte en 1990, penchait pour les années 1220, Christine Ferlampin-Acher propose pour sa part de repousser sa composition vers 1280: l'une et l'autre hypothèse s'appuient sur des éléments internes au texte, somme toute trop vagues pour permettre de trancher de façon définitive (voir ici, pp. 32-44). Malgré une fortune limitée sous sa forme versifiée (l'existence d'un deuxième manuscrit est attestée par les inventaires des ducs de Bourgogne de 1467-68 et 1487), Guillaume de Palerne a joui d'un succès relatif surtout au-delà de la Manche: une traduction en vers anglais, vers 1360, a été suivie d'une réécriture en prose anglaise en 1520-29, puis d'une version en prose irlandaise au XVI ${ }^{e}$ siècle; en France, Pierre Durand en a donné une mise en prose transmise uniquement par des imprimés: la première édition n'est cependant pas celle d'olivier Arnoullet (Lyon, 1552), indiquée ici, mais - comme l'a rappelé encore récemment Sergio Cappello - une édition parisienne, due à Jean Trepperel, et remontant aux années 1527-30 (c'est d'ailleurs l'exemplaire appartenu à Fernand Colomb, cité p. 48).

4 Les thèmes et motifs de Guillaume de Palerne le rattachent indubitablement au folklore d'une part, à la littérature médiévale de l'autre. On y reconnaît en effet des analogies avec la légende de saint Eustache et celle de Romulus et Rémus, mais aussi des échos intertextuels ponctuels avec le Chevalier au Cygne, Guillaume d'Angleterre, déjà cité, ou plus à l'arrière-plan le Roman de Renard (pp. 48-65). Parmi les thèmes analysés par Christine Ferlampin-Acher, rappelons la question du déguisement et du rapport homme / animal (pp. 65-72), et le problème plus subtil du rapport instauré entre nature et norreture d'un côté, entre samblance / nature / estre de l'autre (pp. 72-83). Un paragraphe à part (pp. 84-89) porte sur la modalité de réécriture adoptée par l'auteur médiéval: s'agit-il de "parodie» ou de "pastiche»? Les pages consacrées au traitement des «armes» (90-96) et aux «amours» (96-108) offrent quelques éléments de réponse: si une vision parodique semble avoir marqué la présentation du loup-garou, c'est plutôt la reprise pastichée qui se relève dans les autres cas. En conclusion, Guillaume de Palerne «tient de l'anthologie littéraire» (p. 108), une anthologie où les pratiques intertextuelles et les reprises folkloriques semblent vouloir contribuer à fonder un nouveau type romanesque, en renouvelant «l'horizon d'attente du genre» (p. 112).

Dans l'ensemble, cette Introduction a le grand mérite de faire le point sur les questions fondamentales soulevées par un roman «pas comme les autres»; on regrette cependant un certain nombre de redites (les éléments relatifs à la datation, par exemple, sont repris deux fois dans les mêmes termes: pp. 32-43 et pp. 110-112) et quelques imprécisions: à propos de l'inventaire de la bibliothèque des ducs de Bourgogne, un double renvoi à Barrois aurait été nécessaire (p. 21: seul le n. 1362 est cité, alors que le ms. de Guillaume de Palerne est cité aussi sous le n. 2139; en revanche, p. 41, seul l'inventaire de 1487 est nommé); ou à propos du marquis de Paulmy, ancien possesseur du ms. unique, qui a traité de Guillaume de Palerne dans ses Mélanges tirés d'une grande bibliothèque (vol. D, 1780, pp. 119-150); le Marquis est cité ici p. 35, sans aucun renvoi: «pour le marquis de Paulmy, Yolent serait une sœur de Baudouin VI...»). Restent quelques coquilles: «... le souci de superposer deux registres qui chacun montre des humains métamorphosés en animal...», p. 20; dans la note 5, ainsi que dans la bibliographie finale, on lira Le Moyen Âge par le Moyen Âge, même, et non pas Le Moyen Âge revu par le Moyen Âge (recueil d'articles paru chez Champion en 2012).

6 La traduction, dont les principes sont clairement exposés (pp. 113-114) se base sur l'édition Micha: elle renvoie très utilement aux vers. Elle est suivie d'une Bibliographie 
(pp. 277-281), d'un Index des notions et motifs (pp. 283-284; on y trouvera des entrées aussi diverses que Forêt et Manuscrit BnF Arsenal, Mariage et Miniatures, Tutoiement, vouvoiement et Vêpres Siciliennes...), d'un Index des œuvres (p. 285) et d'un Index des noms propres (il s'agit d'un complément à l'édition Micha: p. 287). 